\title{
Application of Structured Analysis Real Time Method on a Natural Gas Station
}

\author{
M.N LAKHOUA \\ Université de Tunis El Manar, \\ Ecole Nationale d'Ingénieurs de Tunis, \\ LR11ES20 ACS, Tunisie \\ MohamedNajeh.Lakhoua@enit.rnu.tn
}

\author{
Z. SALAH \\ Université de Tunis, ESSTT, \\ 5 Avenue Taha Hussein \\ Montfleury 1008, Tunisie \\ zaara.salah@yahoo.fr
}

\begin{abstract}
The aim of this paper is to present the application of the method of structured analysis and real time (SA-RT) on a control-command application using supervisory control and data acquisition systems (SCADA). Then, the concepts of the SCADA system and its architecture are presented. An example of a control-command application of the supervision of the natural gas in a thermal power plant in Tunisia is presented and analyzed using the SA-RT formalism. Finally, this analysis enables us to facilitate the different steps of the programming and the configuration of the tabular in a SCADA environment.
\end{abstract}

Keywords-SCADA architecture, structured analysis, real time, natural gas station.

\section{INTRODUCTION}

Supervisory control and data acquisition systems (SCADA) are widely used in industry for supervisory control and data acquisition of industrial processes. The process can be industrial, infrastructure or facility [1].

The SCADA system usually consists of the following subsystems [2]:

- A Man-Machine Interface (MMI) is the apparatus which presents process data to a human operator, and through this, the human operator, monitors and controls the process.

- A supervisory system, acquiring data on the process and sending commands to the process.

- Remote Terminal Units (RTU) connecting to sensors in the process, converting sensor signals to digital data and sending digital data to the supervisory system.

- Communication infrastructure connecting the supervisory system to the RTU.

In fact, most control actions are performed automatically by RTU or by programmable logic controllers (PLC). Host control functions are usually restricted to basic overriding or supervisory level intervention. For example, a PLC may control the flow of cooling water through part of an industrial process, but the SCADA system may allow operators to change the set points for the flow, and enable alarm conditions, such as loss of flow and high temperature, to be displayed and recorded [3-5]. The feedback control loop passes through the RTU or PLC, while the SCADA system monitors the overall performance of the loop.
The objective of this paper is to show interests of the use of SCADA systems in power systems. The next section briefly presents the different project management phases (identification of need; initiation; definition; design; acquisition and project closeout) of SCADA projects. Finally, we present and discus a case study of the architecture of a SCADA system in a thermal power plant.

\section{ARCHITECTURE OF A SCADA SYSTEM}

One of the effective tools in power network automation is the SCADA system [6]. In fact, the different equipments, including SCADA system, have been installed in many companies over the world in order to modernize their power system distribution networks [7-10].

In this part we present an example of the architecture of a SCADA system in a thermal power plant in Tunisia. So, we present on the one hand, the different steps of programming in a SCADA environment and on the other hand, the configuration of the tabular of the control-command application.

In fact, the architecture of the SCADA system of a thermal power plant (Fig. 1) is constituted of following elements:

- A plate of bornier;

- FBM (Field Bus Module);

- FCM (Field Bus Communication Module);

- CP60 (Control process);

- DNBT (Dual Node Bus base_T interface);

- AW (Work Station Processor);

- WP (Application Work Station).

Among software of the SCADA system, we mention:

- SYS MON: System monitor that supervises the good working of all the facilities of the system.

- FOXVIEW: Interfacing operator to visualize the tabular with a slim rod to activate the main functions of the SCADA system.

- FOX DRAW: creator of tabular.

- FOX SELECT: Software permitting to reach the various elements of the hierarchy of the data base of the CP60. 
- ICC (Integrated Control Configuration): Software permitting to create and to configure programs residing in the CP60.

- AIM HISTORIAN: Software permits to collect, to organize and to protect data for storage, it also permits to configure features of points to archive, as messages partners to events.

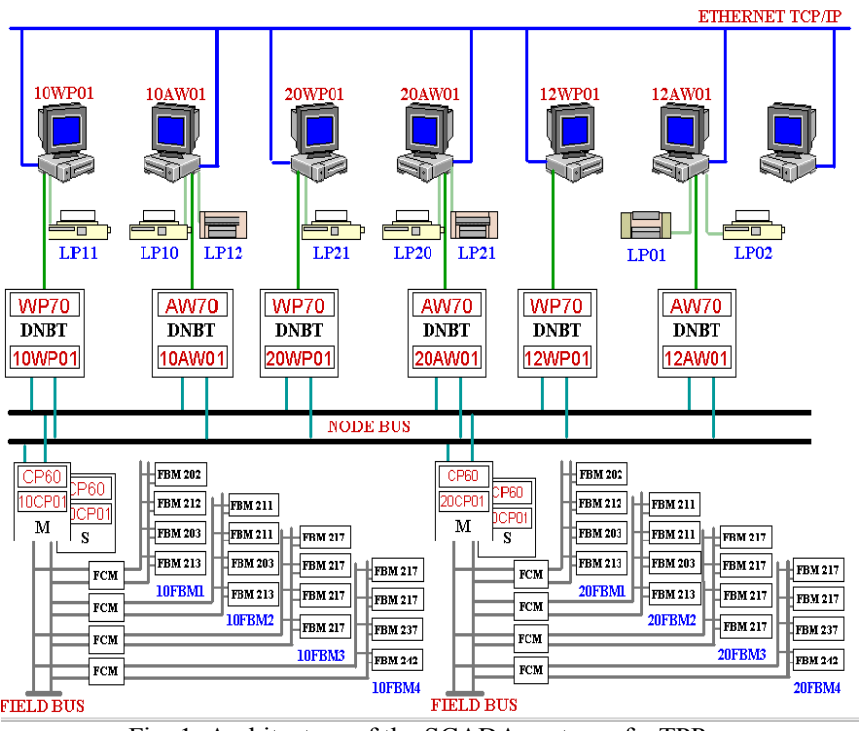

Fig. 1. Architecture of the SCADA system of a TPP.

Among software of the SCADA system, we mention:

- SYS MON: System monitor that supervises the good working of all the facilities of the system.

- FOXVIEW: Interfacing operator to visualize the tabular with a slim rod to activate the main functions of the SCADA system.

- FOX DRAW: creator of tabular.

- FOX SELECT: Software permitting to reach the various elements of the hierarchy of the data base of the CP60.

- ICC (Integrated Control Configuration): Software permitting to create and to configure programs residing in the CP60.

- AIM HISTORIAN: Software permits to collect, to organize and to protect data for storage, it also permits to configure features of points to archive, as messages partners to events.

\section{PRESENTATION OF THE SA-RT METHOD}

Among the graphical methods most commonly used in industry, two of the leading methods are SA-RT and Statecharts.

SA-RT is a short name for Structured Analysis Methods with extensions for Real Time. The model is represented as a hierarchical set of diagrams that includes data and control transformations (processes). Control transformations are specified using State Transition diagrams, and events are represented using Control Flows.
The other graphical and state based paradigm for specification of real time systems is Statecharts. The system is represented as a set of hierarchical states instead of processes. Each state can be decomposed into sub states and so on. The statecharts notation is more compact than the SART notation and has been formally defined.

Thus, SA-RT [11-12] is a complex method for system analysis and design. This is one of the most frequently used design method in technical and real-time oriented applications adopted by various Case-Tools. It is a graphical, hierarchical and implementation independent method for top-down development (Fig. 2).

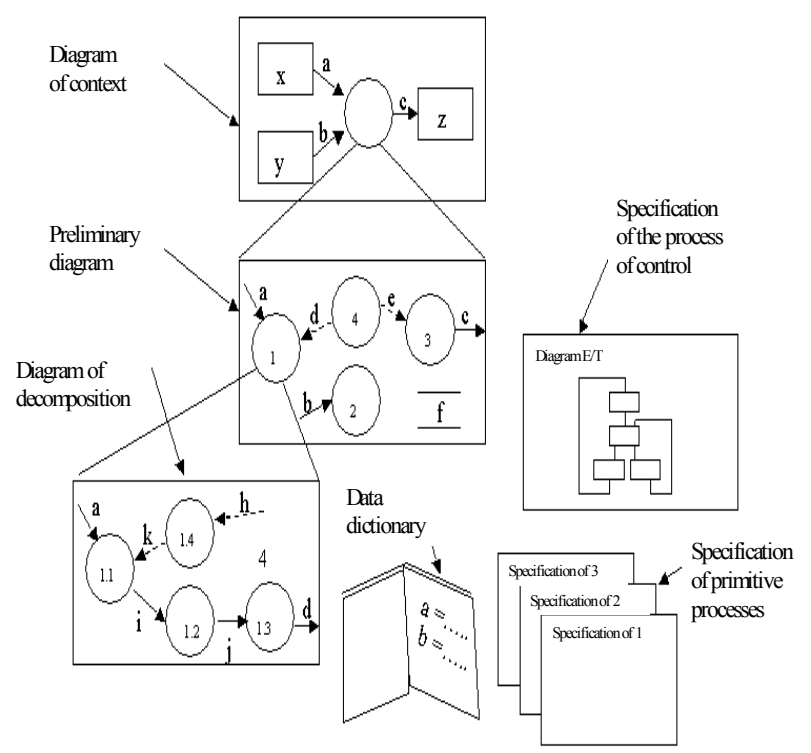

Fig. 2. Organization of an SA-RT model.

SA-RT method enables us to identify an entrance and an exit of data in an algorithm or a computer program. It is divided in three modules: Diagram of Context, Data Flows Diagram and Control Flows Diagram. Every module includes in its graphic interpretation different symbols.

Indeed, the Context Diagram in the SA-RT method is going to enables us to identify a process in a program in relation to the entered and exits of data. This process can have different units. This process will be able to be identified per seconds, in term of constant or variable but as this process will be able to be material type (Process interfacing).

The different symbols used in the Context Diagram of the SA-RT method are [13-14]:

- The terminator is the element in end, final element that encloses the action.

- The data flow is the final element that opens up on a last action.

- The control flow is generally a tie back of the process toward the terminator. It can be a main element of the process.

The termination is generally a direct tie between a terminator and the process. 


\section{CASE STUDY OF A COUNTING SYSTEM OF THE NATURAL GAS}

The different generation sources in the Tunisian electrical system are: hydroelectric, co-generation, renewable (biomass, solar and wind), Natural Gas (NG) thermal power, and others including diesel, oil and coal. The decision to invest in power generation projects, especially in NG thermal power generation, involves a series of issues and challenges. In fact, the real need for thermal power capacity is determined by the combination of energy supply and demand curves.

NG is the fastest growing primary energy source in the world. It is the more used than fuels and coal in the TPPs. It is more manageable and it presents dangers and a bigger explosion risks. The exploitation of the NG requires a structure, of equipments, of instruments and an automatic control.

One of the main features of the utilization of the NG in a TPP is constituted by the importance of volumes clear soups. The research of precision in the measures volumes of gas became then as much for the supplier as for the consumer a necessity. The first interest of the precise numbering of gas is the control of invoicing. The second interest, own to the TPP is the establishment of the complete economic control of the power plant. The third interest is to have a picture of the load produced currently; the important debits are in general measured by the volumetric counters.

The Centre de Production de l'Electricité de Radès (C.P.E.R) is nourished in NG from the Tunisian network of distribution. In fact, the gas undergoes several operations of preparation (Fig. 3) before being introduced in the steam generator, it must be filtered, rehash, relaxed and counted.

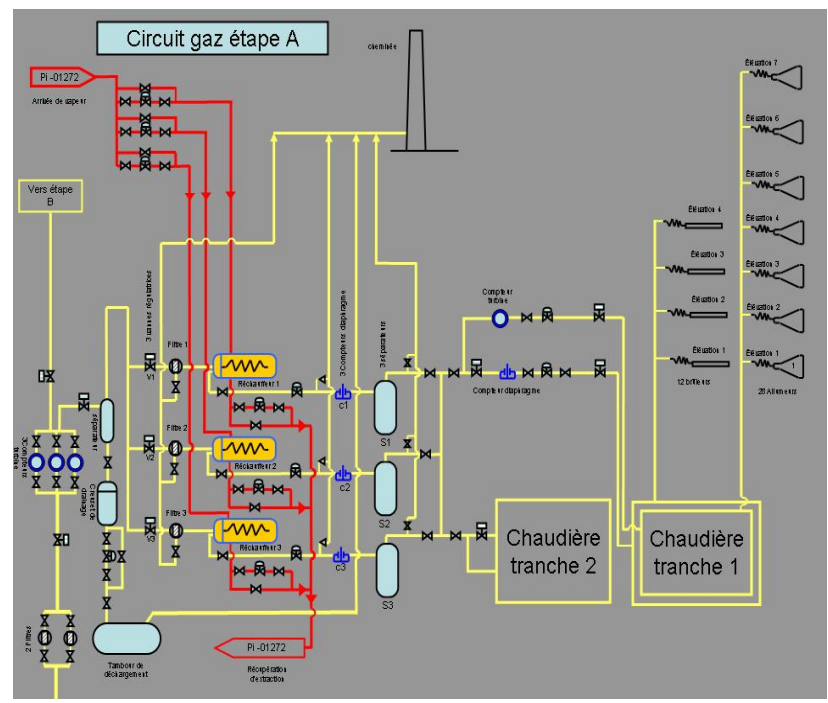

Fig. 3. Display of the NG of a TPP.

The pressure of the NG nourishing burners and lighters vary according to the rate of combustion asked of 1.5 to 2.2 bars, gas arrives to the C.P.E.R to a pressure understood between 15 and 20 bars. It is therefore necessary to loosen it in order to have a neighboring pressure of 4 bars before the regulating floodgate. A second distinct détente for each generator of steam adjusting the pressure of the order of 2 bars has the uphill of the regulating floodgate of debit of NG.

The détente of gas can provoke, according to types of regulator and the conception of détente stations, of noises that are transmitted and amplified sometimes by pipelines, can reach some inadmissible levels for the man and for the good holding of the material. In the critical cases, one decreases the importance of this phenomenon while immediately choking noises in mufflers rooms after regulators. A regulation of arrival of the calorific flux (fluid of heating) is necessary in order to maintain a temperature understood between $15^{\circ} \mathrm{C}$ and $20^{\circ} \mathrm{C}$ after détente. This temperature corresponds to the one of the numbering.

A separator, placed in head of the station, assures a first elimination of foulness can be transported by the NG generally the separator is slim of a decantation pot. Filters assure the final operation. These filters have an important role in beginning of exploitation. Dusts and oxide of iron contents in pipelines of gas are progressively driven toward the primary détente station.

All the time, in facilities where gas circulates with big speed these filters are indispensable of the fact of the continuous practice of oxides that would risk to damage regulators and burners.

Floodgates of security are used in facilities to multiple lines, they are placed upstream of every regulator, and they serve to isolate the line of détente in case of defect. The floodgate of security is ordered by the pressure of the gas of the circuit downstream, therefore the closing of this floodgate depends solely on the order of pressure of declenchment of the floodgate and must make him in consideration of the influence of losses of load and the possible state of the regulator according to the debit of NG.

The objective of the SCADA system of the C.P.E.R is to collect data instantaneously of their sites and to transform in signals and numeric impulse and to send them through the network of communication toward the main and secondary stations. Indeed, the received data by the SCADA system only present $20 \%$ of the existing data totality.

In order to facilitate the different steps of the programming and the configuration of the tabular of the natural gas system, we presented an application of the SART method.

\section{RESULTS OF THE SA-RT ANALYSIS}

In this paragraph, we present an application of the SART method for the analysis of a control-command application using the functional and operational applications of control analysis SA-RT method.

Compared to the results given by other methods such as SADT (Structured Analysis Design Technique), the SA-RT method allows a functional as well as a temporal analysis. Then, the case study of the natural gas system of the thermal 
power plant is analyzed according to the SA-RT formalism presented.

After modeling of the natural gas system of the TPP using the SA-RT method, we establish four diagrams as follows:

- Context diagram of the natural gas system;

- Data flow diagram of the natural gas system;
- Control flow diagram of the natural gas system;

- State-transition diagram of the natural gas system.

Figure 4 presents the context diagram of the SA-RT model of the natural gas system. In fact, the context diagram is constituted of one functional process « To pilot the natural gas system $0 \gg$ and 17 terminators.

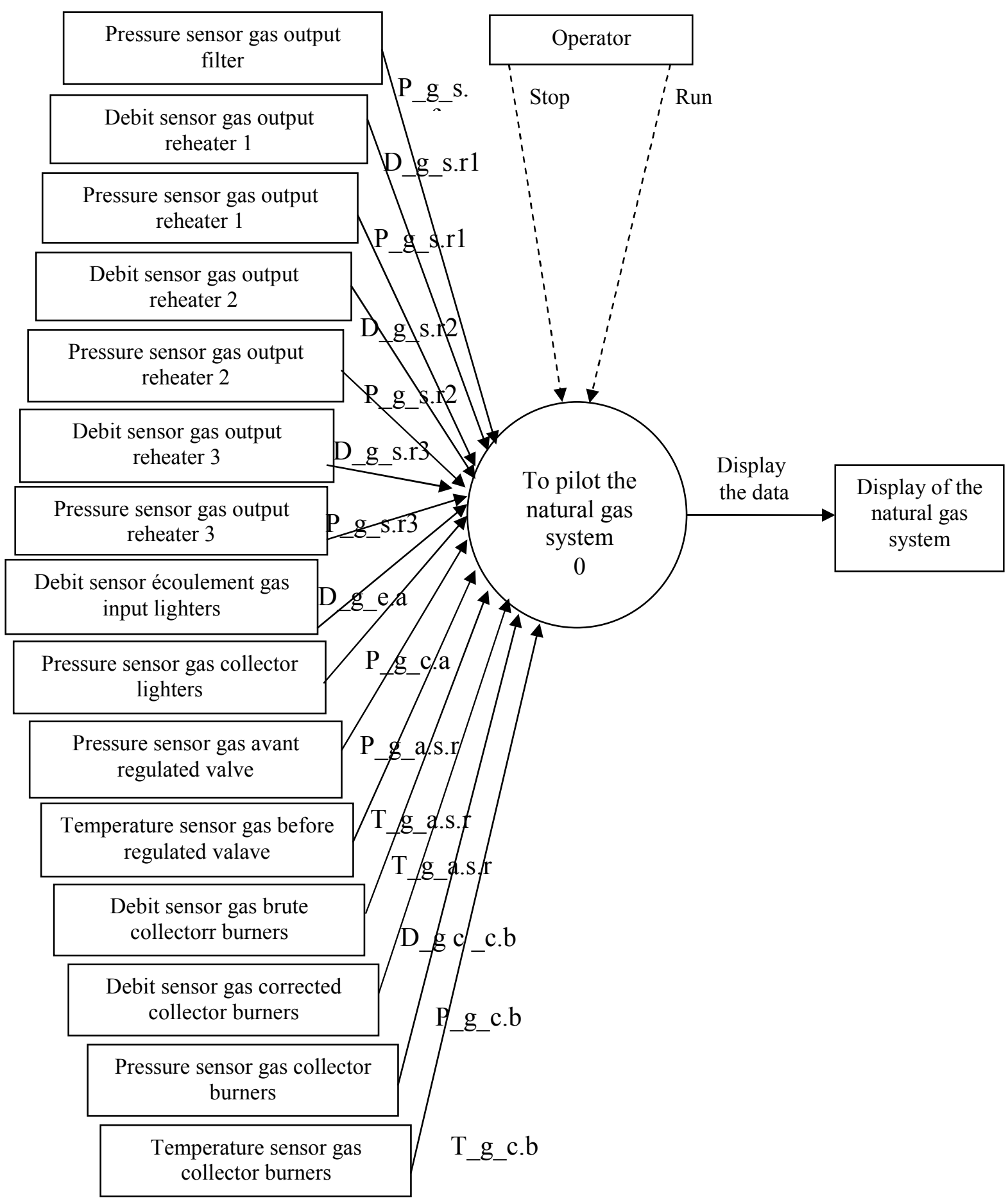

Fig. 4: Context diagram of the SA-RT model of the natural gas system. 
List of terminators:

Terminator «Sensor pressure gas output filter» provide the data «Pressure gas output filter (P_g_s.f) »;

Terminator «Sensor debit gas output reheater 1» provide the data «Debit gas output reheater 1 (D g s.r1)»;

Terminator «Sensor pressure gas output reheater 1» provide the data «Pressure gas output $\mathrm{r} 1$ (P_g_s.r1) »;

Terminator «Sensor debit gas output reheater 2 » provide the data «Debit gas output reheater 2 (D_g_s.r2)»;

Terminator «Sensor pressure gas output reheater 2 » provide the data «Pressure gas output reheater 2 (P_g_s.r2)»;

Terminator «Sensor debit gas output reheater 3» provide the data «Debit gas output reheater 3 (D_g_s.r3) »;

Terminator «Sensor pressure gas output reheater 3» provide the data "Pressure gas output reheater 3 (P_g_s.r3)»;

Terminator «Sensor debit gas input lighters» provide the data « Debit gas input lighters (D_g_e.a)»;

Terminator «Sensor pressure gas collector lighters» provide the data «Pressure gas collector lighters (P_g_c.a) »;

Terminator «Sensor pressure gas before regulated valve » provide the data "Pressure gas before regulated valve (P_g_a.s.r)»;

Terminator «Sensor temperature gas before regulated valve » provide the data «Temperature gas before regulated valve (T_g_a.s.r) »;

Terminator «Sensor debit gas collector bruleurs » provide the data «Débit gaz brût collecteur burners (D g b c.b) »;

Terminator «Sensor debit gas corrected collector burners » provide the data «Debit gas corrected collector burners (D g c c.b) »;

Terminator «Sensor pressure gas collector burners» provide the data «Pressure gas collector burners (P_g_c.b) »;
Terminator «Sensor temperature gas collector burners» provide the data «Temperature gas collector burners (T_g_c.b) »;

Terminator «Display of the natural gas system » consume the data «Display the data ».

The context diagram defines perfectly the interface between the designer and the client, that is, to provide or generate data in order to display these data on the tabular of the natural gas system.

The Data flow diagram (Fig. 5) of the SA-RT model constitutes the first decomposition of the process presented in the context diagram. Then, we can break down the initial functional process of the application of control in three basic elements: Acquirement process; Treatment process; Human-Machine interfacing process.

Figure 6 presents the Control flow diagram of the SA-RT model that includes the control aspect to the data flow diagram elaborated. In fact, the implementation of the process of monitoring at the level of preliminary diagram can express the execution or the sequence of the functional processes.

The possible uses for the SA-RT model are the design of a monitoring display and a diagnosis display. For the design of a monitoring display, the preliminary data flow diagram of the SA-RT model supplies a global view of the system. Indeed, information relative to each process represented through this level should appear in a monitoring display.

For the design of hierarchical diagnosis display, each data flows diagram of the SA-RT model constitutes a vision at a given abstraction level. So, each of these data flows diagrams gives a less or more detailed vision. In function of the objectives defined by the designer for each display, a particular data flows diagram can supply the required information.

Finally, this application of the functional analysis technique on the SCADA system of a TPP shows briefly the interests of the SA-RT method in the design of supervisory systems.

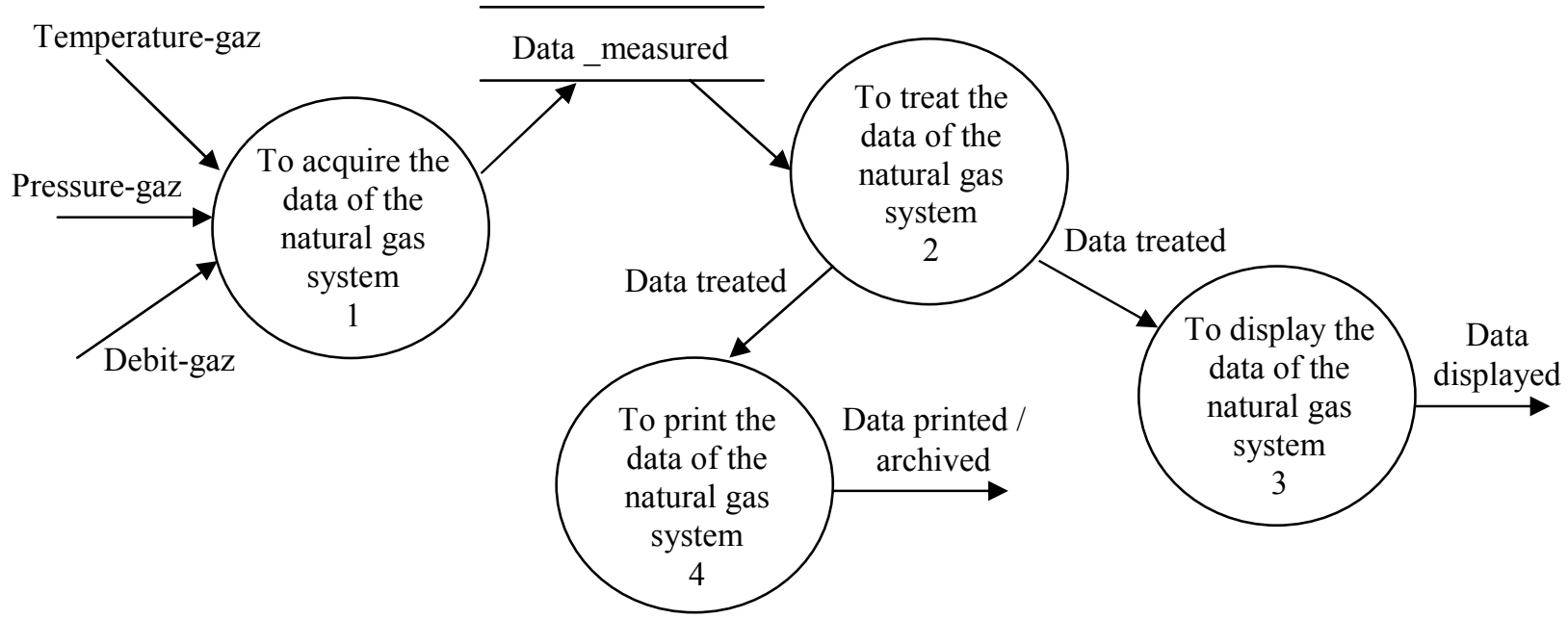

Fig. 5. Data Flows Diagram of the SCADA system. 


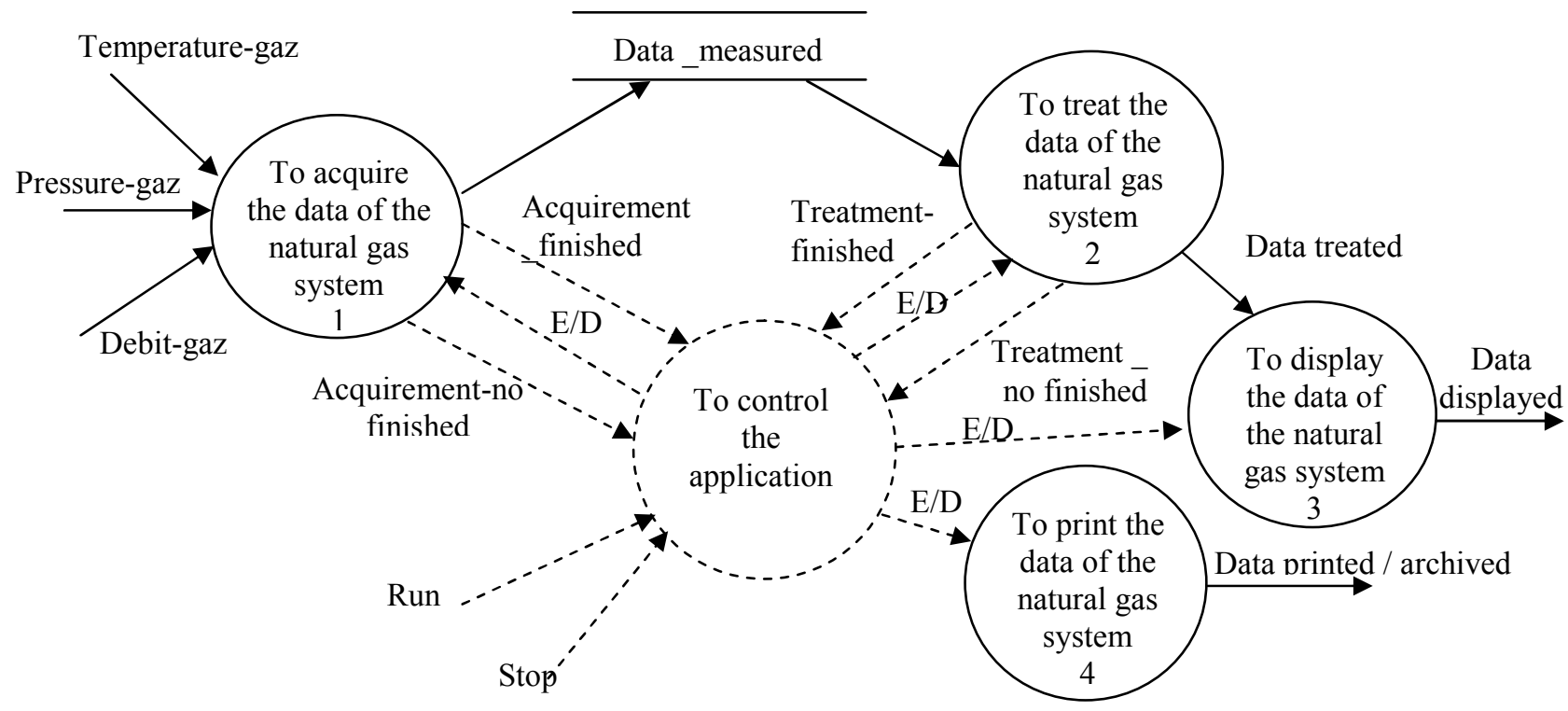

Fig. 6. Control Flows Diagram of the SCADA system.

Figure 7 presents the state-transition diagram of the SART model of the natural gas system.

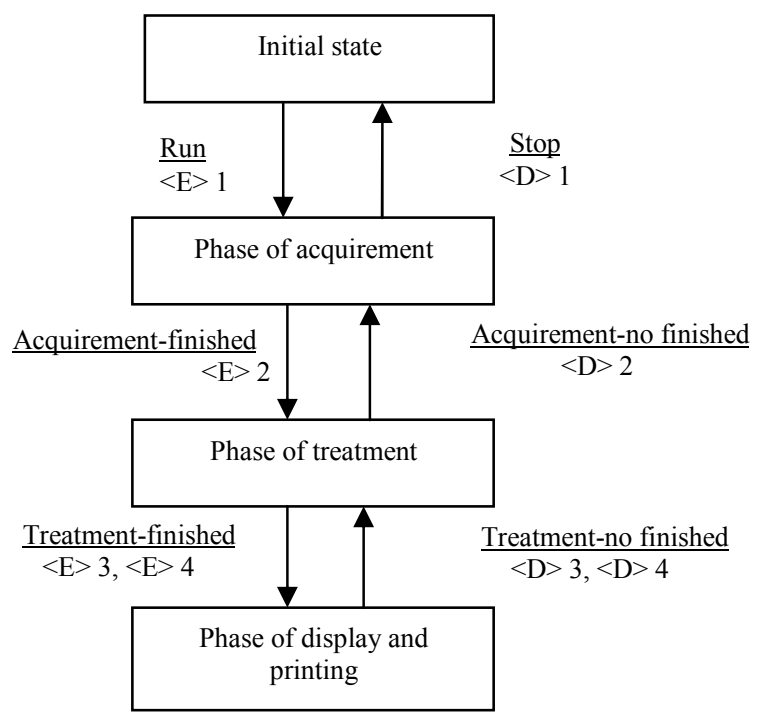

Fig. 7. State/Transition diagram of a SCADA system.

\section{CONCLUSION}

In this paper, we presented on the one hand, the functionality of a SCADA system and on the other hand, an analysis of a control-command application using the SA-RT method. In fact, it is very important to use software of the SCADA system for the programming and the configuration of the tabular in a SCADA environment.

The SA-RT analysis will allow an easy stage of a parametric modeling and implementation through the development of a control algorithm helping in the design of a supervising and monitoring system of the natural gas station.

Staring from this case study of the architecture of a SCADA system discussed in this paper, work is in progress to develop a functional analysis and real time for the various applications of control-command in a thermal power plant.

\section{REFERENCES}

[1] Bailey D. and Wright E., Practical SCADA for Industry, Elsevier, 2003.

[2] Clarke G., Reynders D. and Wright E., Practical Modern SCADA Protocols, Elsevier, 2003.

[3] Wiles J., Techno Security's Guide to Securing SCADA: A Comprehensive Handbook On Protecting The Critical Infrastructure, Elsevier, 2008.

[4] Warcuse J., Menz B. and Payne J. R., Servers in SCADA applications, IEEE Trans. Ind. Appl. 9-2, 1997.

[5] Chan E. K. and Ebenhon, H., The implementation and Evolution of a SCADA System for a Large Distribution Network, IEEE Transactions on Power systems, Vol.7, No.1, 1992, pp.320-326.

[6] Patel M., Cole G. R., Pryor T. L. and Wilmota N. A., Development of a novel SCADA system for laboratory testing, ISA Transactions 43, 2004, pp 477-490.

[7] Marchat H., La gestion de projet par étapes - Portefeuille de projets, Editions d'Organisation, 2009.

[8] Lakhoua M.N., Application of Functional Analysis on a SCADA system of a Thermal Power Plant, AECE Journal, Issue No2/2009, vol. 9.

[9] Lakhoua M.N., Application of Functional Analysis Techniques and Supervision of Thermal Power Plants, Thermal Power Plants, Mohammad Rasul (Ed.), ISBN: 978-953-307-952-3, InTech, 2012.

[10] Lakhoua M.N., SCADA applications in thermal power plants, IJPS, vol.5, N7, 2010, pp 1175-1182.

[11] Jaulent P., Génie logiciel les méthodes : SADT, SA, E-A, SA-RT, SYS-P-O, OOD, HOOD, Armand Colin, 1992.

[12] Sommerville I., Le génie logiciel et ses applications, InterEditions, France, 1988.

[13] Sticklen J., William E., Functional Reasoning and Functional Modelling, IEEE Expert: Intelligent Systems and Their Applications, pp. 20 - 21, 1991.

[14] Strohmeier A., Buchs D., Génie logiciel : principes, méthodes et techniques, Presses polytechniques et universitaires Romandes, Lausane 1996. 